Counsellia: Jurnal Bimbingan dan Konseling, 9 (1), 2019| 65- 78

Copyright (C2019 Universitas PGRI Madiun

ISSN: 2088-3072 (Print) / 2477-5886 (Online)

Available online at: http://e-journal.unipma.ac.id/index.php/JBK

DOI: $10.25273 /$ counsellia.v9i1.4300

\title{
Pendekatan Tazkiyatun An-Nafs untuk membantu mengurangi emosi negatif klien
}

\author{
Alfaiz $^{1}$, Hengki Yandri ${ }^{2}$, Asroful Kadafi ${ }^{3}$, Rila Rahma Mulyani ${ }^{4}$, Nofrita $^{5}$, Dosi \\ Juliawati $^{6}$ \\ ${ }^{1}$ STKIP PGRI Sumatera Barat, Sumatera Barat \\ alfaiz@ stkip-pgri-sumbar.ac.id \\ ${ }^{2}$ Institut Agama Islam Negeri Kerinci, Kerinci \\ hengki@iainkerinci.ac.id \\ ${ }^{3}$ Universitas PGRI Madiun, Madiun \\ asrofulkadafi@unipma.ac.id \\ ${ }^{4}$ STKIP PGRI Sumatera Barat, Sumatera Barat \\ rila@stkip-pgri-sumbar.ac.id \\ ${ }^{5}$ Universitas Langlangbuana, Bandung \\ nofrita40@gmail.com \\ ${ }^{6}$ Institut Agama Islam Negeri Kerinci, Kerinci \\ dosi@ konselor.org
}

\begin{abstract}
Abstrak
Emosi merupakan kondisi psikologis yang bersumber dari dua faktor dalam hidup manusia, yaitu adanya faktor internal dan eksternal. Faktor internal merupakan aspek bawaan dan genetik, yang mana tidak bisa dipisahkan dari bagaimana individu berperilaku dan merespon, akan tetapi bisa di bentuk dan dikendalikan. Serta faktor eksternal merupakan pengaruh lingkungan yang mempengaruhi persepsi subjektif dan komunikasi sosial individu. Kondisi ini merupakan dinamika manusia dalam hidupnya akan tetapi juga bisa menjadi bencana dalam hidup sosial, banyak masalah yang muncul dari manusia yang tidak bisa mengatur emosi mereka dalam berperilaku emosi ini dikenal dengan emosi negatif dalam islam disebut dengan nafsu lawammah dan amarrah. Banyak teknik konseling yang telah dilakukan untuk membantu klien dalam membantu klien mengatur meosi negatifnya tapi teknik tersebut hanya menyentuh permukaan dari kesadaran individu itu saja tetapi tidak menyentuh transendennya diri klien seperti akhlak dan pemikiran yang mendalam akan diri klien. Seperti yang disampaikan oleh Assagioli dengan psikologi transpersonalnya bahwa pikiran dan keinginan diri merupakan diri yang transenden. Begitu juga Al Ghazali mengatakan dalam Tazkiyatun An-Nafs akhlak merupakan pikiran dan hati yang mendalam untuk membantu membentuk emosi positif dan melepaskan yang negatif. Dalam artikel ini akan didiskusikan secara lebih mendalam mengenai emosi, dan aspeknya serta bagaimana tazkiyatun an-nafs bisa disintesiskan sebagai pendekatan konseling untuk membantu melepaskan emosi negatif klien serta artikel ini juga merupakan pengembangan dari artikel sebelumnya di tahun 2017 yaitu mengenai sufism approached in school counseling service: an analysis of perspective spiritual counseling kata kunci: konselor, emosi negatif, tazkiyatun an-nafs, spiritual counseling.
\end{abstract}

Kata Kunci: Konselor, Emosi Negatif, Tazkiyatun An-Nafs, Spiritual Counseling 


\begin{abstract}
Emotion was a psychological condition that came from two factor in human life, internal and external factor. Internal factor was a gift and genetic aspect, that can not be seperated from how an individual to behave and react, but can be shape and control and external factor was an environment influence that affect a subjective perception and social communication of individual. This condition can be a human dynamica in their life but also can be a disaster in social life, there are many problem came from how individual can not control or manage their emotion to behave in their life, this emotion call a negative emotion, in islam call such nafsun lawammah and amarrah. Many technique has been done to help the client in manage of their negative emotion, but that technique only touch on a surface of client's counscioussness but not a trancendence of their self such an akhlak and deepest mind. Like told by Assagioli in transpersonal psychology that mind and will was a trancendence of self and al ghazali with tazkiyatun an-nafs approach told that akhlak was an deepest mind and heart to shape a positive emotion and release a negative emotion. In this article will discuss for further about emotion and their aspect and also how tazkiyatun an-nafs approach can be a synthesis to help release a negative emotion of client, this article was expanded from article in 2017 before that discuss about sufism approached in school counseling service: an analysis of perspective spiritual counseling kata kunci : konselor, emosi negatif, tazkiyatun annafs, spiritual counseling.
\end{abstract}

Keywords : Counselor, Negative Emotion, Tazkiyatun An-Nafs, Spiritual Counseling

\section{PENDAHULUAN}

Sesuai dengan pemahaman kita selama ini manusia dibekali dengan kemampuan kognitif, emosi dan psikomotor, salah satu yang sangat mempengaruhi dalam perilaku dan pengambilan keputusan pilihan dalam hidup yang mencerminkan kecerdasan seseorang adalah emosi. Emosi merupakan gejolak perasaan dan hasrat bisa berupa positif bisa negatif untuk merespon situasi lingkungan. Gejolak emosi negatif yang dimunculkan individu harus dipahami oleh pendidik khususnya orang tua dan guru di sekolah yaitu dengan cara memahami karakteristik individu dan menghindari sebabsebab terjadinya emosi negatifnya (Elida, 2006:69).

Dalam Al Quran Allah SWT menjelaskan bahwa: "demi jiwa serta penyempurnaan (ciptaan)nya, maka Dia mengilhamkan kepadanya (jalan) kejahatan dan ketakwaan, sungguh beruntung orang yang menyucikan (jiwa itu), dan sungguh rugi orang yang mengotorinya" (Q.S Asy-Syams: 7-10), berdasarkan surat tersebut jelas bahwa setiap individu diberikan pilihan dan keterbukaan untuk memilih jalan takwa atau kejahatan, jalan takwa adalah mereka yang mampu mengelola kemampuan kognitif, emosi dan perilakunya, berusaha untuk memelihara kondisi emosi dalam ranah kebaikan dan positif, dan juga tidak tertutup kemungkinan untuk jalan kejahatan yaitu emosi negatif.

Berdasarkan hal tersebut, emosi yang merupakan bawaan manusia yang bersifat genetik dan juga menjadikan manusia berdasarkan faktor lingkungan, merupakan aspek psikologis yang tidak bisa kita pungkiri, bahwasanya manusia mampu memberikan pengaruh 
kepada orang lain dalam kebaikkan karena individu memiliki kecenderungan kebaikan dan juga bisa menjadi jahat karena Allah SWT juga menganugerahkan jalan kejahatan pada diri manusia itu sendiri. Kejahatan yang dilakukan manusia juga disebabkan oleh lingkungan itu sendiri, hal ini disebabkan oleh interaksi manusia dengan lingkungan dan kebudayaannya. Dengan kata lain, lingkungan bisa mempengaruhi negatif kondisi psikologis manusia dalam hal emosinya, dan juga memberikan pengaruh yang positif bagi emosi dan perilaku manusia itu sendiri dalam hal ini bagi generasi muda. Satu hal lain yang dapat membentuk suatu emosi negative yaitu rasa tanggung jawab yang dimiliki oleh individu, yang tentunya juga akan berdampak negative bagi rgenerasi muda (Kadafi \& Ramli, 2017).

Melihat kompleksitas masalah yang ditimbulkan oleh lingkungan pada masa globalisasi ini, banyaknya berita bohong (hoax), banyaknya pengaruh budaya asing seperti budaya pola pikir pendidikan dan politik mengenai post truth hampir sama dengan kondisi berita bohong yang lama kelamaan menjadi benar sehingga fakta tidak lagi dihiraukan dibanding aspek emosi negatif diri tentang realita di era revolusi industri 4.0 sekarang (Utomo, 2017). Oleh karena itu perlu diberikan dan disintesiskan suatu pendekatan konseling yang berlandaskan Islam dan Tasawuf. Dalam hal ini yaitu pendekatan Tazkiyatun An-Nafs yang memiliki pemahaman manusia sebagai wujud yang transenden dan bisa memiliki dorongan self correction. Hal ini sudah menjadi penting dikembangkan kembali dari artikel sebelumnya pada tahun 2017 , akan tetapi itu masih berupa penggeneralisasikan konsep sufistik dalam proses konseling yang belum terlalu spesifik dalam pelayanan dan tahapan konseling, maka pada artikel kali ini akan dijelaskan secara spesifiknya dalam konteks praktikalitas konseling tazkiyatun an nafs.

\section{METODE}

Metode yang digunakan dalam analisis ini adalah metode library research dan literatur studi yang dilakukan dengan mnganalisis dari berbagai sumber referensi dan menarik suatu analisis dengan tajam dan kritis sehingga melahirkan sintesis yang bisa di lihat rasional dan logisnya menjadi sesuatu yang bisa di uji dilapangan.

Metode ini dilakukan dengan mengambil beberapa referensi yang berkaitan dengan pandangan tasawuf dan tazkiyatun an nafs dari beberapa buku referensi dan referensi jurnal dan artikel sintesis lainnya sehingga mempertajam analisis dan dasar sintesis dari studi ini. 


\section{HASIL DAN PEMBAHASAN \\ Emosi dan Bentuknya}

Chaplin (2006:163) menjelaskan bahwa emosi adalah suatu respons yang kompleks saling berkaitan timbal balik sehingga terjadi perubahan secara mendalam pada seseorang yang disertai dengan perasaan yang kuat. Pengalaman yang subjektif dan dialami didasarkan pada sudut pandang seseorang yang berkaitan dengan perasaan, perilaku, suasana hati, pengambilan keputusan, temperamen dan karakter merupakan emosi (Rahayu, 2015:5). Mengenai itu dijelaskan dalam Al Quran yaitu: "Banyak wajah pada hari itu berseri-seri, tertawa dan bergembira ria, dan banyak pula wajah pada hari itu tertutup debu, dan ditutup lagi oleh kegelapan" (QS. Abasa:3841).

Setiap rangsangan yang terjadi terhadap individu sehingga terjadi perubahan secara fisiologis yang disertai perasaan yang kuat dan biasanya memungkinkan untuk meluap disebut dengan emosi (Asrori, 2009:82). Kemudian Qodratillah (2011:4230) menyatakan bahwa emosi merupakan luapan perasaan yang bisa berkembang dan surut dalam waktu singkat. Selanjutnya William James (Sobur, 2009:399) memaknai emosi sebagai satu kecenderungan pada manusia untuk memiliki perasaan yang khas jika berhadapan dengan objek tertentu di lingkungannya.
Berdasarkan hal tersebut, dapat kita menarik pemahaman bahwa emosi merupakan kondisi dan proses psikologis yang terjadi pada diri manusia yang melalui proses stimulus respon dari lingkungan terhadap diri manusia dan dicerna melalui keterlibatan kognitif yang disebut dengan persepsi. Keterlibatan kognitif dan perasaan ini merupakan kondisi interaksi akal dan hati manusia dalam perilaku sehari-hari, hal ini perlu menjadi perhatian utama jika ingin membantu klien dan bahkan membantu diri sendiri bahwasanya kondisi emosi negatif tidak lepas dari bagaimana individu mengenal dirinya baik secara negatif maupun positif, maka pendekatan Islam perlu rasanya dikembangkan untuk bisa melepaskan emosi negatif dan menumbuhkembangkan emosi positif manusia. Cole (Elida, 2006:69) dan John B Watson (Sobur, 2009: 410) mengemukakan tiga bentuk emosi yaitu sebagai berikut:

a. Marah

Emosi marah dipengaruhi oleh faktor-faktor belajar dan proses tumbuh dewasa yang dijalani oleh seseorang yang bisa di pahami sebagai reaksi tekanan perasaan (Jersild dalam Sobur, 2009:413). Bentuk dari reaksi emosi marah seperti beringas, mengamuk, benci, dengki, iri, jengkel, kesal, tersinggung, permusuhan, tidak senang dengan orang lain, dan lain sebagainya. 


\begin{abstract}
Rasulullah SAW sudah mengingatkan dalam sebuah hadits: Abu Said Al Khudri meriwayatkan bahwa Rasulullah SAW bersabda, "Ingatlah bahwa marah adalah bara api di dalam hati anak Adam. Tidaklah kalian melihat kedua matanya yang memerah dan urat lehernya yang menegang”. (HR. Tirmidzi dalam Najati: 2008:109). Bahwasanya emosi marah merupakan sifat bawaan yang ada pada manusia yang harus di kelola dengan baik, jika itdak ingin membawa kepada kebinasaan kepada manusia yang menjerumuskannya pada masalah psikologis dan fisik serta sosial.
\end{abstract}

\section{b. Takut}

Bentuk dari emosi takut seperti cemas, gugup, khawatir, was-was, sedih, waspada, tidak tenang, panik, phobia, tidak nyaman, dan lain sebagainya. Sebenarnya emosi takut yang paling tinggi tingkatannya yaitu emosi takut kepada Allah SWT akan pedihnya siksaan Allah kepada hamba-hambanya yang durhaka kepadanya, hal ini diingatkan Allah dalam Al Quran "Takutlah kepada-Ku, jika kamu benar-benar orang yang beriman" (QS. Ali Imran, 175). Emosi takut pada tingkat yang normal akan memotivasi individu untuk sesuatu perbuatan baik sedangkan emosi takut yang pada tingkat berlebih akan berpotensi memunculkan keresahan yang berefek buruk pada kualitas hidup manusia (Najati, 2008: 105). Oleh karena itu rasa takut perlu di jaga dan di menej, karena Allah SWT tidak setuju jika seuatu hal tersebut berlebihan dan tidak juga tidak sama sekali, oleh karena itu rasa takut perlu dan juga tidak boleh berlebihan, karena semua perilaku dan sikap manusia berada pada rasa takut, takut bisa menjadi motivator bagi diri sendiri dan juga menjadi tujuan hidup manusia sehingga mereka bisa menjadi lebih berhati-hati dalam bertindak dan bersikap.

\section{c. Cinta}

Bentuk dari emosi cinta seperti penerimaan, persahabatan, kasih sayang, gembira, hormat, kasmaran, senang, girang, dan lain sebagainya. Rasulullah SAW menganjurkan manusia untuk untuk menempatkan cinta tertinggi kepada Allah SWT, beliau bersabda, "Cintailah Allah karena Dia telah memberimu makanan dari nikmat-nikmat Nya" (HR. Tirmidzi dalam Najati, 2008:82).

Seperti yang dijelaskan oleh pepatah para sufi bahwa barang siapa yang mengenal dirinya maka mereka akan mengenal tuhannya hal ini menekankan bahwa ketika idividu 
mengenal betapa berartinya hidup dan dirinya, maka dia akan mengenal bahwa dia dimiliki oleh maha Mecintai yaitu Allah SWT. Sehingga hal ini menyatakan bahwa rasa Cinta merupakan emosi yang memunculkan bahwa diri kita dan yang lainnya merupakan sesuatu yang baik maka emosi ini jika dikembangkan dengan baik akan munculnya rasa menghargai dan menyayangi dalam kehidupan.

\section{Gangguan Emosi}

Emosi pada manusia tidak selamanya bisa stabil terkadang juga mengalami gangguan yang membuat manusia menjadi tidak nyaman. Gangguan emosi terjadi karena pandangan yang negatif dan tidak logis, yang diyakini atau tidak mengenai problem yang dihadapi, bisa karena ketidak tahuan atau tidak biasa (Sobur, 2009:409). Kemudian Menurut Elida (2006:74) beberapa penyebab yang sering menimbulkan gangguan emosi pada seseorang yaitu:

1. Merasa kebutuhan fisik tidak terpenuhi secara baik yang menyebabkan ketidaknyamanan, khawatir, dan benci terhadap kondisi diri.

2. Merasa tidak diterima, tidak disukai, dan kurang diingini.

3. Adanya perasaan dihambat, diacuhkan, dihina, serta dilemahkan dari pada di dukung dan dimotivasi pendapatnya.
4. Merasa inferior pada kemampuan diri

5. Merasa tidak merasa nyaman dengan kehidupan keluarganya

6. Adanya perasaan dengki dan benci dengan kehidupan orang lain.

\section{Intelegensi Emosi}

Kecerdasan emosi adalah suatu kapabilitas seseorang untuk memahami, empati terhadap kondisi emosi orang lain dan juga daya serta kepekaan emosi yang dijadikan sebagai kekuatan dan mempengaruhi baik pada individu (Carv dan Peter dalam Thalib, 2010:108). Orang yang cerdas secara emosi memungkinkan dirinya mampu menggunakan dan memanfaatkan emosinya dengan baik dan benar.

Goleman (Hamid, 2013:148) menempatkan kecerdasan emosi adanya lima kapabilitas penting yaitu:

\section{Mengenali Emosi Diri}

Mengenali emosi diri sendiri adalah kapabilitas untuk mengidentifikasi perasaan itu ketika perasaan itu muncul. Kemampuan ini membuat seseorang waspada terhadap suasana hati atau pikiran yang sering disebut dengan kesadaran diri. Apabila individu kurang sadar, dia akan mudah tenggelam dalam emosinya sehingga mereka korban dari emosi dirinya sendiri. 


\section{Mengelola Emosi}

Mengelola emosi adalah kapabilitas individu dalam mengatur dan menghandel perasaannya dengan baik agar mampu mengekspresikan dengan tepat dan selaras sehingga tercipta kestabilan dalam dirinya.

\section{Memotivasi Diri Sendiri}

Memotivasi diri sendiri memiliki makna bahwasanya individu harus memiliki kekuatan untuk menahan diri terhadap kepuasan dan mengendalikan suasana hati sehingga memiliki motivasi yang positif seperti antusiasme, optimis dan keyakinan.

\section{Mengenali Emosi Orang Lain}

Kemampuan ini juga disebut dengan empati. Orang yang memiliki kemampuan empati mampu menangkap makna dan hakikat sosial yang tersembunyi, bertanda apa yang dinginkan oleh orang lain, sehingga ia mampu menerima sudut pandang orang lain, peka terhadap perasaan orang lain, dan lebih kapabel mendengarkan orang lain.

\section{Membina Hubungan}

Kapabilitas dalam menjalin dan membangun hubungan yang merupakan keterampilan untuk menunjang komunikasi sosial, kepemimpinan dan keberhasilan interpersonal..

\section{Implementasi Tazkiyatun An-Nafs dalam Pelayanan Konseling}

Sarana penyucian jiwa (Tazkiyatun An-Nafs) diantaranya yang mendekati dalam pendekatan aplikasi psikologi konseling Islam, Shalat, Puasa, Membaca Al Quran, Zikir, Tafakkur, Mengingat Hidup itu pendek, Muraqabah-MuhasabahMujahadah-Mu'aqabah, Mengenal Penyakit Hati diri (Hawwa, S. 2007).

Penyucian jiwa yang diajukan oleh Al Ghazali merupakan konsep konseling atau penyembuhan jiwa yang didasari pada prinsip tasawuf akhlaki yang mana merupakan salah satu dari tiga aliran besar tasawuf yang diantaranya adalah tasawuf falsafi dan tasawuf irfani (Alfaiz, 2017: 3). Setiap aliran memiliki pandangan berbeda untuk melakukan penyucian jiwa dengan tujuan yang sama yaitu menemukan ketenangan, kebahagiaan dan kedekatan diri kepada Allah SWT. Dalam perspektif tasawuf, kondisi psikologis atau kejiwaaan manusia yang berimplikasi pada tingkah lakunya itu semua disebabkan karena adanya hambatan dan gangguan dalam akal dan hati untuk mencapai nur ilahi. Seperti halnya dalam pandangan aliran tasawuf akhlaki yang menekankan pada penyucian jiwa atau dikenal Tazkiyatun An-Nafs esensi dari pemahaman ini adalah inti dari perilaku dan akhlak manusia adalah bagaimana kondisi hati manusia itu sendiri (Hawwa, S, 2007; Alfaiz, 2017: 3). Hati adalah 
raja yang bisa membuat sipemilik hati menjadi sangat sholeh dan bisa juga membuat si pemilik hati menjadi sangat keji ( Hambali A, et al, 2004; Adz Dzaky, 2002). Sehingga jika hati merupakan penyebab utama dari munculnya perilaku dan akhlak buruk manusia dalam kehidupan sosial, maka hati perlu dibersihkan dengan penuh kesadaran, konsistensi, dan keinginan untuk berubah (Alfaiz, 2017: 3). Begitu juga hati yang sehat dan cakupan makna sehat memang sulit ditemukan secara fisik, psikis, sosial dan spiritual kecuali pribadi baginda Rasulullah Muhammad SAW hal ini karena beliau terjaga dan dijaga oleh Allah SWT (Yuliyatun, 2014:340) hal ini perlu kita tiru dan usaha untuk menjaga diri kita dengan meneladani Rasulullah.

Dalam pandangan psikologi yang memiliki kesamaan persepsi mengenai bagaimana pemikiran dan jiwa menentukan perilaku manusia, hal ini juga dijelaskan oleh Assagioli yang merupakan ahli psikoterapi transpersonal psychology yang meintegrasikan nilai spiritualitas dalam konsep psychosynthesis yang menyatakan self (diri) merupakan kekuatan internal individu yang dibangkitkan oleh will (hasrat). Will ini merupakan hati dan intensional diri individu sehingga individu melahirkan seperti halnya imajinasi, pemikiran, dorongan, emosi yang terealisasi semuanya dalam bentuk perilaku sehari-hari (Alfaiz, Hidayat, R, Zulfikar, Hariko, 2017:3; Shorrock, A: 2008). Serta juga secara filosofis kondisi psikologis manusia juga didorong oleh faktor eksternal manusia itu sendiri seperti lingkungan sosial-budaya individu tersebut dan kebiasaannya. Sebagai sebuah ilmu, konseling memahami manusia tidak hanya bebas nilai melainkan juga memahami manusia terikat akan nilai (Alfaiz, 2018: 42).

Keterikatan akan nilai ini yang menjadi salah satu potensi munculnya perilaku dan kecenderungan emosi negatif dari manusia atau klien, kembali pada konsep tasawuf akhlaki yaitu penyucian jiwa yang disampaikan oleh Al Ghazali adanya beberapa proses yang perlu dipahami dan dilaksanakan baik oleh konselor sebagai fasilitator yang mensugestif klien maupun klien sebagai individu yang diberikan pelayanan dengan pendekatan spiritual tasawuf ini. Berikut penjelasan proses tazkiyatun an-nafs, akan tetapi sebelum memasuki proses konseling, klien perlu memiliki kesadaran terlebih dahulu yaitu

a) Intensional, Meskipun manusia memiliki ketergantungan dengan lingkungan sosialnya, akan tetapi manusia juga memiliki kesadaran penuh dan melakukan dialog dalam dirinya disetiap perilaku yang mereka lakukan sehingga melahirkan keyakinan diri (Adz Dzaky, 2002: 303; 
Alfaiz \& Yandri, H. 2015: 216). Intensional ini mendukung berjalannya proses konseling untuk membantu klien.

b) Pengakuan Diri, Sebelum pelaksanaan konseling tazkiyatun an-nafs klien perlu disadarkan dan diajak untuk berfikir mengenai hakikat hidup dan hasrat dari diri. Hal ini bertujuan agar klien menyadari bahwa tidak adanya tindakan free will yaitu tindakan oleh kehendak diri sendiri, dengan ini maka klien menyadari bahwa adanya kekuatan besar (devine power) yang mengontrol, menentukan dan mewujudkan setiap usaha dan menghisab segala perbuatan sehari-hari klien selama dia hidup di dunia (Hawwa, S. 2004; Alfaiz, 2017).

c) Hasrat Kecendrungan untuk

Baik/Berubah, Jika klien sudah mengakui dirinya merupakan makhluk ciptaan, dan mengakui bahwa adanya kesalahan dan perilaku serta emosi negatif yang perlu diubah, maka konselor perlu mensugestif klien untuk siap akan kecenderungan ke arah positif dan baik.

Jika tiga hal tersebut sudah dimiliki oleh klien sebelum dilaksanakan pelayanan konseling tazkiyatun an nafs, hal ini bisa melalui instrumen skala/angket perilaku dan emosi negatif dan bisa juga melalui wawancara instrospeksi diri klien terlebih dahulu. Setelah itu terlaksana, maka konselor bisa mengaplikasikan pendekatan tazkiyatun an nafs, berikut sintesis proses pelaksanaan layanan konseling tazkiyatun an nafs (Hawwa, S. 2007; Hambali A, et al, 2004).

Tabel 1. Proses Tahapan Pelayanan Menggunakan Skill Pendekatan Spiritual Tazkiyatun An Nafs dalam Konseling

\begin{tabular}{|c|c|c|c|}
\hline No & $\begin{array}{c}\text { Tahapan } \\
\text { Pelayanan }\end{array}$ & Kegiatan Konselor & Kegiatan Klien/Klien \\
\hline 1 & $\begin{array}{l}\text { Takhalli }(\text { Self } \\
\text { Cleansing })\end{array}$ & $\begin{array}{l}\text { - } \text { Membangun rapport yang baik pada } \\
\text { klien } \\
\text { - Mewawancarai klien akan } \\
\text { kebiasaan perilaku dan kebiasaan } \\
\text { emosi yang dilakukan oleh klien } \\
\text { dan juga berdasarkan observasi } \\
\text { selama ini } \\
\text { - Sugestif klien untuk mengakui } \\
\text { perilaku tercelanya } \\
\text { - Mewawancarai klien untuk } \\
\text { mengungkapkan hambatan dan } \\
\text { gangguan untuk berubah } \\
\text { - Mengajak klien untuk secara sadar } \\
\text { agar komitmen untuk mengubah } \\
\text { setiap perilaku dan emosi yang }\end{array}$ & $\begin{array}{l}\text { - } \text { Mengikuti kegiatan } \\
\text { pelayanan secara serius } \\
\text { - Menceritakan kebiasaan } \\
\text { perilaku negatif dan emosi } \\
\text { negatif sehari-hari yang } \\
\text { perlu diubah dan menyadari } \\
\text { keinginan untuk berubah } \\
\text { - Klien menyadari perubahan } \\
\text { perilakunya tergantung pada } \\
\text { pikiran dan hatinya } \\
\text { - Menceritakan hambatan dan } \\
\text { gangguan dalam dirinya } \\
\text { - Klien memotivasi dirinya } \\
\text { untuk mengidentifikasi } \\
\text { perilaku dan emosi }\end{array}$ \\
\hline
\end{tabular}




\begin{tabular}{|c|c|c|c|}
\hline & & $\begin{array}{l}\text { ingin diubah seperti halnya proses } \\
\text { taubat }\end{array}$ & $\begin{array}{l}\text { negatifnya dan siap untuk } \\
\text { membersihkan dirinya }\end{array}$ \\
\hline 2 & $\begin{array}{l}\text { Tahalli } \\
\text { Filling) }\end{array}$ & $\begin{array}{l}\text { - Memotivasi klien agar memiliki } \\
\text { efikasi diri yang kuat untuk mampu } \\
\text { menjadi lebih baik dalam } \\
\text { mengontrol emosi dan perilaku } \\
\text { negatif } \\
\text { - Melatih klien untuk perilaku yang } \\
\text { baik yang sesuai tuntunan dalam } \\
\text { konsep penyucian jiwa tasawuf } \\
\text { akhlaki } \\
\text { - Memberikan pelatihan dan } \\
\text { pemahaman Taubat akan perilaku } \\
\text { negatif selama ini } \\
\text { - Memberikan pelatihan dan } \\
\text { pemahaman akan hakikat Sabar } \\
\text { agar mampu mengontrol emosi } \\
\text { negatif pemanan dan } \\
\text { - Memberikan pemahaman } \\
\text { latihan bagaimana berperilaku } \\
\text { Zuhud yaitu mencukupkan diri } \\
\text { dengan yang ada menghilangkan } \\
\text { perilaku tamak dan sombong } \\
\text { - Memberikan pemahaman dan } \\
\text { latihan untuk Ihsan dalam setiap } \\
\text { niat dan tindakan sehari-hari } \\
\text { - Memberikan sugesti positif setiap } \\
\text { usaha klien untuk berubah dan } \\
\text { konsisten a }\end{array}$ & $\begin{array}{l}\text { - Klien meyakinkan diri } \\
\text { dengan sadar bahwa salah } \\
\text { satu yang bisa membantu } \\
\text { diri adalah kesadaran akan } \\
\text { adanya kekuatan diluar } \\
\text { dirinya } \\
\text { - Menyadari bahwa hati dan } \\
\text { pikiran adalah penyakit } \\
\text { yang merusak perilaku dan } \\
\text { emosi jika sangat tergantung } \\
\text { dengan lingkungan } \\
\text { - Memahami dan melatih diri } \\
\text { untuk bertaubat dari } \\
\text { perilaku negatif } \\
\text { - Memahami hakikat Sabar } \\
\text { dalam hidup, sabar akan apa } \\
\text { yang diinginkan maupun } \\
\text { sabar akan yang tidak } \\
\text { diinginkan dan } \\
\text { - Memahami dan } \\
\text { mempribadikan makna } \\
\text { Zuhud dalam perilaku } \\
\text { sehingga munculnya pribadi } \\
\text { yang tenang dan bahagia } \\
\text { akan apa yang diperoleh } \\
\text { - Memahami dan menyadari } \\
\text { bahwa kekuatan diluar diri } \\
\text { selalu menjaga } \\
\text { mengawasi dan } \\
\text { - Menjadikan dirinya sehata } \\
\text { secara fisik dan psikis }\end{array}$ \\
\hline 3 & $\begin{array}{l}\text { Tajalli } \\
\text { Reborn) }\end{array}$ & $\begin{array}{l}\text { - Menyimpulkan hasil pelayanan } \\
\text { konseling tazkiyatun an nafs dengan } \\
\text { membimbing klien untuk mampu } \\
\text { melaksanakan semua self filling tadi } \\
\text { dalam kehidupan sehari-hari } \\
\text { - Memberikan nasehat pada klien } \\
\text { agar konsisten untuk menjaga } \\
\text { pribadi dan perilaku yang positif } \\
\text { tersebut meskipun banyak gangguan } \\
\text { dari lingkungan, dan selalu lakukan } \\
\text { kontemplasi setiap setelah ibadah } \\
\text { - Menutup proses pelayanan dan } \\
\text { membuka pertemuan berikutnya } \\
\text { jika klien membutuhkan } \\
\text { - Mengevaluasi lapangan klien dalam } \\
\text { kesehariannya }\end{array}$ & $\begin{array}{l}\text { - } \text { Melakukan dengan } \\
\text { konsisten perilaku baru di } \\
\text { sekolah dan di rumahnya } \\
\text { - Mengkonsultasikan setiap } \\
\text { hambatan dan progres } \\
\text { pengalaman spiritualnya } \\
\text { selama perubahan yang } \\
\text { dilakukannya } \\
\text { - Melakukan proses } \\
\text { kontemplasi disetiap setelah } \\
\text { ibadah dengan self talk }\end{array}$ \\
\hline
\end{tabular}

Tahapan disetiap proses tazkiyatun an nafs merupakan tahapan pendekatan tasawuf akhlaki yang meliputi proses pengakuan diri, 
introspeksi diri, serta komitmen diri untuk berubah. Banyak individu apapun status sosialnya, pekerjaannya dan dilingkungan apapun mereka, mereka terhambat untuk melakukan proses spiritual ini dalam dirinya karena adanya defence mechanism (Shorrock, 2008; Alfaiz et. al 2017) hal ini dikarenakan adanya pembelaan diri bahwa diri sudah benar dan baik, merasa diri tidak salah. Dalam pandangan Islam, kecenderungan ini disebut dengan takabur dan ini yang menghambat mata batin dan pikiran manusia untuk bisa melaksanakan proses penyucian jiwa.

Tahapan takhalli, merupakan tahapan awal dari proses penyucian jiwa yaitu tahapan yang paling berat karena pada tahap ini klien diajak untuk membuka tabir/hijab negatif dirinya yang selama ini terhambat untuk mereka akui. Sehingga disebut dengan self cleansing (Alfaiz, 2017: 4). Mereka harus mengakui dan bisa menyampaikan dengan assertif bahwa dirinya memiliki perilaku negatif yang selama ini dia benarkan. Tahap ini merupakan tahapan melepaskan diri dari belenggu kemunafikan dan ketika klien melepaskan ini maka ada kepuasan hati yang akan membantunya pada tahap tahalli.

Tahapan tahalli, merupakan tahapan pengisian diri dengan nilai, perilaku dan pola pikir yang baik agar klien bisa menjaga dan mempertahankan sikap dan perilaku positifnya dalam kehidupan seharihari. Tahap ini harus diimbangi dengan kekonsistensian dan komitmen klien untuk menutup segala kemungkinan negatif dirinya (Hambali et al, 2004; Alfaiz, 2017). Pada tahap ini klien mengenal dan mengisikan pada dirinya perilaku taubat, sabar, zuhud dan ihsan sehingga perpaduan aspek tersebut menjadikan dirinya terjaga dan terpelihara dari kecenderungan negatif.

Tahapan tajalli, merupakan tahapan terakhir dan juga tahapan penentu dari proses tazkiyatun an nafs, hal ini dikarenakan tahap ini adalah usaha menstabilkan diri dengan realita dunia yang sangat berbeda dengan pribadi yang baru lahir melalui proses penyucian jiwa ini (Hambali et al, 2004). Pada tahap ini klien konsisten dengan perubahannya sehingga semakin menghadapi realita dunia maka semakin mempribadinya perubahan baik dirinya tersebut.

\section{SIMPULAN}

Berdasarkan diskusi dan pembahasan yang telah disintesiskan di atas, maka bisa dipahami bahwa tazkiyatun an nafs merupakan pendekatan sufistik yang berbasis pada aliran tasawuf akhlaki yang melihat asal muasal perilaku manusia dari pikiran dan hati manusia bukan hanya dari piikiran saja. Serta tahapan dalam proses konseling tazkiyatun an nafs jika disebut 
sebagai konseling merupakan proses dimana adanya pengakuan diri (assertif) akan kelemahamn dan kesalahan diri yang selama ini menjadi penghambat untuk berubahnya pribadi seseorang, sehingga meruntuhkan defence mechanism itu sendiri, introspeksi diri dalam setiap proses, dan komitmen diri untuk berubah dan konsisten dengan realita yang harus dihadapi dengan cara baru dirinya beperilaku.

Jika disimpulkan pendekatan tazkiyatun an nafs bisa dijadikan salah satu teknik atau pendekatan konseling karena mencakup tidak hanya ranah psikoanalisa dalam hal defence mechanism melainkan juga dalam kognitif, behavioral hingga spiritual konseling yang menjadikan pendekatan ini bisa diaplikasikan dalam proses konseling. Meskipun ini berupa sintesis dan analisis dari kajian tasawuf yang berimplikasi pada konseling Islam, yang masih butuh proses eksperimen untuk dikatakan layak guna, akan tetapi sintesis ini bisa dijadikan acuan untuk mengujinya dilapangan secara spesifik.

\section{DAFTAR PUSTAKA}

Alfaiz. (2014). Pembelajaran Afektif Merupakan Salah Satu Strategi Dalam Pembentukkan Karakter Peserta Didik. Jurnal Pelangi, Vol. 7, No. 1, 94-105. http://ejournal.stkip-pgrisumbar.ac.id/index.php/pelan gi/article/view/152. DOI: https://doi.org/10.22202/jp.20 14.v7i1.152.

Alfaiz, D., \& Yandri, H. (2015). Self Concept and Self Efficacy As A Ground Points in A Social Activities (An Analysis of Psychology Perspective: A Social Cognitive Theory). Jurnal Pelangi, 7(2), 45-52. http://ejournal.stkip-pgrisumbar.ac.id/index.php/pelan gi/article/view/203. DOI: https://doi.org/10.22202/jp.20 15.v7i2.203.

Alfaiz. A, Rafiola. R.H, Hariko. R, \& Zulfikar. Z. (2017). Condition and Shaping of Student Personality in Educational Process Through Transpersonal Psychology Perspective. Proceedings of The 3rd International Conference on Education and Training (ICET 2017). https://www.atlantispress.com/proceedings/icet17/25883491. https://doi.org/10.2991/icet17.2017.1

Alfaiz. (2017). Sufism Approached in School Counseling Service: An Analysis of Perspective Spiritual Counseling. Schoulid: Indonesian Journal of School Counseling. 2(1): pp. 1-7. https://doi.org/10.23916/0086 21423-00-0.

http://journal.konselor.or.id/i ndex.php/schoulid/article/vie $\mathrm{w} / 42$. 
Alfaiz, A. (2018). Guidance and Counseling Profession: a Philosophy and Professional Challenges In The Future. Couns-Edu: International Journal of Counseling and Education, 3(1): pp. 44-47. DOI:

https://doi.org/10.23916/0020 180313420.

http://journal.konselor.or.id/i ndex.php/counsedu/article/vie w/134.

Asrori, M. (2009). Psikologi Pembelajaran. Bandung: Wacana Prima.

Berg, R.C., Landreth, G.L., \& Fall, K.A. (2006). Group Counseling Concepts and Procedures (Fourth Edition). New York: Taylor \& Francis Group, LLC.

Chaplin, J.P. (2006). Kamus Lengkap Psikologi. Terjemahan: Kartini Kartono. Jakarta: Raja Grafindo Persada.

Departemen Agama RI. (2009). Al Quran dan Terjemahan. Bandung: Sygma Examedia Arkanleema.

Djaali. (2011). Psikologi Pendidikan. Jakarta: Bumi Aksara.

Elida, P. (2006). Psikologi Perkembangan Remaja. Padang: Angkasa Raya.

Geldard, K \& Geldard, D. (2008). Konseling Anak-Anak; Panduan Praktis. Alih bahasa: Fajar, R. Yogyakarta: Pustaka Pelajar.

Hamid, H. (2013). Pengembangan Sistem Pendidikan di
Indonesia. Bandung: Pustaka Setia.

Hasan, A. B. P. (2008). Psikologi Perkembangan Islami. Jakarta: Raja Grafindo Persada.

Herna, A. (2014). Hebatnya Hipnosis Anak. Jakarta: Panda Media.

Hawwa, S. (2007). Tazkiyatun AnNafs : Kajian Lengkap Penyucian Jiwa. Jakarta: Pena, Ilmu dan Amal.

Kadafi, A \& Ramli, M. (2017). Integrated Qs Al Mudatsir in the reality group counseling to grow the character of students academic responsibility. Counsellia: Jurnal Bimbingan dan Konseling, $\quad 7(2), \quad 117-125$. doi:

http://doi.org/10.25273/couns ellia.v7i2.1867. http://ejournal.unipma.ac.id/index.ph p/JBK/article/view/1867.

Mas'udi, M. (2015). Kedudukan Penyuluhan dan Konselor Dalam Konseling Islam. KONSELING RELIGI Jurnal Bimbingan Konseling Islam, 5(2), 187-206. doi:http://dx.doi.org/10.21043 /kr.v5i2.1047.

http://journal.stainkudus.ac.id /index.php/konseling/article/v iew/1047.

Najati, M. U. (2008). The Ultimate Psychology: Psikologi Sempurna ala Nabi SAW. Bandung: Pustaka Hidayah.

Qodratillah, M. T. (2011). Kamus Bahasa Indonesia untuk Pelajar. Jakarta: Badan Pengembangan dan 
Pembinaan Bahasa Kemendikbud.

Rahayu, I. (2013). Emotional Healing Therapy. Jakarta: Grasindo.

Shorrock, A. (2008). The Transpersonal in Psychology, Psychotherapy and Counseling. New York: Palgrave MacMillan.

Sobur, A. (2009). Psikologi Umum. Bandung: Pustaka Setia.

Supriyanto, A \& Hendiani, N. (2018). Aspect, Validity, and Reliability Family Support Perception Scale for Substance Abuse Disorders. COUNSELLIA, 8 (1). 7-18. DOI:

10.25273/counsellia.v8i1.226

$8 . \quad$ http://ejournal.unipma.ac.id/index.ph $\mathrm{p} / \mathrm{JBK}$

Thalib, B. S. (2010). Psikologi Pendidikan Berbasis Analisis Empiris Aplikatif. Jakarta: Kencana.
Utomo, P.W. (2017). Selamat Datang di Era Post Truth, Kabar Remotivi.

Yuliyatun, Y. (2015). Konstribusi Konseling Islam Dalam Penyembuhan Penyakit Fisik. KONSELING RELIGI Jurnal Bimbingan Konseling Islam, 5(2), 335-352. doi:http://dx.doi.org/10.21043 /kr.v5i2.1054 http://journal.stainkudus.ac.id /index.php/konseling/article/v iew/1054.

Zaini, A. (2014). Urgensi Bimbingan dan Konseling Bagi Remaja (Upaya Pencegahan Terhadap Perilaku Menyimpang). KONSELING RELIGI Jurnal Bimbingan Konseling Islam, 4(2), 371-390. doi:http://dx.doi.org/10.21043 /kr.v4i2.1012.

http://journal.stainkudus.ac.id /index.php/konseling/article/v iew/1012. 